\title{
7 Formação de professores e a Modelagem Matemática na Educação Básica
}

\author{
Carla Melli Tambarussi \\ Tiago Emanuel Klüber
}

\section{SciELO Books / SciELO Livros / SciELO Libros}

TAMBARUSSI, C. M. and KLÜBER, T. E. Formação de professores e a Modelagem Matemática na Educação Básica. In: BRANDT, C. F., BURAK, D., and KLÜBER, T. E., orgs. Modelagem matemática: perspectivas, experiências, reflexões e teorizações [online]. 2nd ed. rev. and enl. Ponta Grossa: Editora UEPG, 2016, pp. 131-145. ISBN 978-85-7798-232-5. Available from: doi: 10.7476/9788577982325.0008. Also available in ePUB from: http://books.scielo.org/id/b4zpq/epub/brandt-9788577982325.epub.

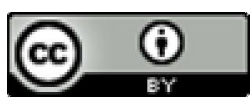

All the contents of this work, except where otherwise noted, is licensed under a Creative Commons Attribution $\underline{4.0 \text { International license. }}$

Todo o conteúdo deste trabalho, exceto quando houver ressalva, é publicado sob a licença Creative Commons Atribição 4.0.

Todo el contenido de esta obra, excepto donde se indique lo contrario, está bajo licencia de la licencia $\underline{\text { Creative }}$ Commons Reconocimento 4.0. 


\title{
Formação de professores e a Modelagem Matemática na Educação Básica
}

\author{
Carla Melli Tambarussi \\ Tiago Emanuel Klüber
}

\section{Expondo o significado do texto}

É inegável o discurso existente acerca da necessidade em se pensar o processo de ensino e aprendizagem sob outras perspectivas. Isto é, sob aspectos que não exponham o professor à condição de mero "transmissor" do conhecimento e o aluno a simples "espectador" no âmbito da sala de aula.

Essa necessidade de mudança está presente em todas as disciplinas que compõem o currículo escolar, tendo em vista que não basta que os alunos decorem fórmulas, regras gramaticais, classificação dos seres vivos ou quaisquer outros conceitos, conteúdos ou procedimentos sem que haja uma compreensão sobre aquilo que está sendo estudado. Há, portanto, que se pensar em uma escola que proporcione ao aluno autonomia e criticidade, ou seja, um ambiente que lhe possibilite a participação em um processo de ensino e aprendizagem significativo.

Essa problemática apresentada é amplamente reconhecida nas discussões sobre o papel da escola nas últimas décadas e dela emergem, de um modo geral, dois pontos principais e que estão interligados: 1) a busca por diferentes maneiras de abordar o conteúdo; e 2) o empreendimento de estudos e reflexões acerca da formação do professor. Esses pontos se justificam, pelo fato de que se faz necessário pensar em maneiras mais amplas de se trabalhar em sala de aula e que proporcionem uma interação maior, com vistas à aprendizagem, entre aluno e professor. Essa afirmação, por sua vez, incide diretamente na questão da formação do professor, uma vez que muitos deles foram expostos a ambientes formativos conhecidos como tradicionais e que acabam por reproduzir a postura adquirida, nesse contexto, em suas práticas docentes.

Desse modo, nesse trabalho buscamos apresentar algumas reflexões que se direcionam aos pontos problematizados. Em suma, visando abordar o primeiro ponto, que diz dos diferentes modos de abordar os conteúdos, expomos uma das tendências de maior destaque no âmbito da Educação Matemática: a Modelagem Matemática. No que diz respeito ao segundo 
ponto, apresentamos algumas reflexões sobre a formação do professor no que tange essa tendência.

Esse ensaio ${ }^{1}$, portanto, solicita a compreensão da Modelagem Matemática enquanto uma tendência potencialmente significativa para a Educação Básica e de aspectos da legislação e teóricos sobre formação de professores para este nível de ensino. Desde os esclarecimentos em pauta, consideramos pertinente dedicar as duas próximas seções à descrição dos elementos centrais destes dois tópicos, para, somente ao final, apresentarmos reflexões pertinentes ao objeto posto em destaque: A formação de professores e a Modelagem Matemática na Educação Básica.

\section{Modelagem Matemática na Educação Básica}

No cenário educacional brasileiro a história da Modelagem Matemática teve início com os cursos de especialização para professores, em 1983, na Faculdade de Filosofia, Ciências e Letras de Guarapuava - FAFIG (BURAK, 2004).

A partir de então, e com o início do Mestrado em Educação Matemática na UNESP - Rio Claro, a Modelagem

[...] angariou adeptos, pois a grande preocupação sentida consistia em encontrar formas alternativas para o ensino de Matemática que trabalhassem ou que tivessem a preocupação de partir de situações vivenciadas pelos alunos do ensino de $1^{\circ}$ e $2^{\circ}$ graus, atualmente ensino Fundamental e Médio (BURAK, 2004, p. 1).

Essa preocupação citada por Burak, no que diz respeito à busca de modos alternativos de se abordar a Matemática e a necessidade de que essa abordagem esteja relacionada à realidade do aluno, ainda é uma constante quando nos reportamos ao atual contexto escolar. E, também, vai ao encontro do que é exposto nos Parâmetros Curriculares Nacionais

[...] à medida que vamos nos integrando ao que se denomina uma sociedade da informação crescentemente globalizada, é importante que a Educação se volte para o desenvolvimento das capacidades de comunicação, de resolver problemas, de tomar decisões, de fazer inferências, de criar, de aperfeiçoar conhecimentos e valores, de trabalhar cooperativamente (1999, p. 40).

\footnotetext{
${ }^{1}$ Entendemos ensaio como uma "[...] exposição lógica e reflexiva e em argumentação rigorosa e com alto nível de interpretação e julgamento pessoal" (SEVERINO, 2000, p. 152).
} 
Nesse mesmo sentido, as Diretrizes Curriculares do Estado do Paraná explicitam que se faz necessário um "ensino que possibilite aos estudantes análises, discussões, conjecturas, apropriação de conceitos e formulação de ideias" (PARANÁ, 2008, p. 48).

Desse modo, muito do que se lê nos documentos oficiais da educação podem corroborar para a formação de um aluno crítico, capaz de resolver problemas e tomar suas próprias decisões. Essa contribuição se dará na medida em que se adotem, implementem e permaneçam na escola, tendências pedagógicas e metodológicas apropriadas.

É nesse contexto que apresentamos alguns argumentos sobre a inserção da Modelagem Matemática no âmbito escolar, tendo em vista que ela pode proporcionar um processo de ensino e aprendizagem com significado. Isto é, um processo que se volte para a formação de um cidadão crítico, capaz de analisar e interpretar as diversas situações, que deverão ser enfrentadas por ele no mundo em que vive (BURAK; ARAGÃO, 2012).

Barbosa (2001; 2004), ao discutir aspectos favoráveis à inclusão da Modelagem na Educação Básica, destaca cinco pontos: 1) motivação; 2) facilitação da aprendizagem; 3) preparação para utilizar a Matemática em diferentes áreas; 4) desenvolvimento de habilidades gerais de exploração; e 5) compreensão do papel sociocultural da Matemática.

Desde essa apologia ao uso da Modelagem Matemática, na perspectiva da Educação Matemática, também emergem outros discursos, como, por exemplo, o de Burak (1987), quando ressaltou que "o ensino através da Modelagem procura propiciar o emergir de situações-problema às mais variadas possíveis, sempre dentro de um contexto fazendo com que a matemática estudada tenha mais significado para o aluno" (p. 17-18).

O mesmo autor reforça a importância da Modelagem ao elucidar que ela é "[...] um conjunto de procedimentos cujo objetivo é construir um paralelo para tentar explicar matematicamente, os fenômenos presentes no cotidiano do ser humano ajudando-o a fazer predições e tomar decisões" (BURAK, 1992, p. 62). Ainda defende, numa posição específica sobre o ensino e aprendizagem da Matemática, que o interesse é um dos princípios fundamentais de sua perspectiva, de tal maneira que tanto o início como a sequência das atividades estão diretamente relacionados a ele.

A partir dos argumentos, até agora apresentados, revela-se que assumir a Modelagem Matemática no contexto da sala de aula pode significar uma visão mais ampla para o ensino de Matemática, sem que ela fique restrita a um conjunto de fórmulas a serem decoradas ou a um conjunto de conteúdos 
sem relação com o cotidiano do aluno. Nessa perspectiva, D'Ambrósio U. (2002) afirma que ela se constitui em um importante processo para se enfrentar situações, permitindo, assim, a solução efetiva de um problema real e não a resolução de um problema artificial.

Ressaltamos ainda que, o que foi apresentado sobre a inserção da Modelagem Matemática no contexto educacional, vai ao encontro do que as Diretrizes Curriculares do Estado Paraná - DCE - solicitam para o ensino de Matemática. Isto é,

[...] É necessário que o processo pedagógico em Matemática contribua para que o estudante tenha condições de constatar regularidades, generalizações e apropriação de linguagem adequada para descrever e interpretar fenômenos matemáticos e de outras áreas do conhecimento (PARANÁ, 2008, p. 49).

Esses elementos contribuíram, dentre outras coisas, para que a Modelagem fosse considerada uma tendência metodológica ${ }^{2}$ pelas DCE (2008). Em outras palavras, há nesse documento a sugestão de que os conteúdos propostos para o Ensino Fundamental e Médio sejam abordados por meio de tendências da Educação Matemática que fundamentam a prática docente.

De modo a progredirmos nos argumentos deste ensaio adentramos na discussão que é concernente à formação de professores na Educação Básica. Contemplamos, portanto, a legislação específica e generalidades teóricas.

\section{Formação de professores na Educação Básica}

Frente ao que explicitamos acerca da Modelagem Matemática revelase, dentre outros aspectos, que a postura do professor, em um ambiente no qual se opte por trabalhar com essa tendência, precisa ser diferente daquela assumida em um contexto tradicional de ensino e aprendizagem. Para Dias e Almeida (2004) essa mudança se deve ao fato de que cabe ao professor, ao trabalhar com Modelagem, incentivar a comunicação entre os alunos, conhecer o que está sendo desenvolvido durante as atividades, estimular a criticidade e favorecer a procura por argumentos que possam contribuir para que os alunos confirmem ou não suas conjecturas.

Entretanto, essa mudança de postura, de um modo geral, não é algo que se possa alcançar repentinamente. Em outras palavras, podemos dizer

\footnotetext{
${ }^{2}$ Além da Modelagem Matemática, as Diretrizes Curriculares do Estado do Paraná também assumem outras tendências metodológicas: 1) Resolução de Problemas; 2) Mídias Tecnológicas; 3) Etnomatemática; 4) História da Matemática e 5) Investigações Matemáticas.
} 
que há alguns aspectos que acabam dificultando que essa mudança seja posta em prática. Um deles são os próprios professores, que por vezes se mostram resistentes à implementação de novas propostas pedagógicas no âmbito da sala de aula. Essa resistência pode ser justificada, dentre outros aspectos, pelo fato de os professores não conseguirem superar a forma como tiveram contato com o ensino de Matemática durante a sua vida escolar. E, desse modo, ficarem acomodados em um ambiente no qual possam reproduzir práticas tradicionais, sem uma postura reflexiva sobre o que eles têm desenvolvido em suas aulas.

Outra condição relacionada à essa dificuldade está no formato dos programas de Licenciaturas em Matemática que estão, segundo Meyer, Caldeira e Malheiros (2011), em sua maioria, presos às concepções cientificistas e que influenciam as práticas educacionais vigentes.

Em complemento a essa afirmação, Fiorentini (1994) destaca que nas décadas de 1970 a 1980 há no Brasil a predominância de uma concepção tecnicista. E de acordo com Klüber (2012, p. 71) "assumindo que uma cultura não muda repentinamente para outra distinta é razoável afirmar que essa concepção, mesmo com mudanças, ainda permanece na escola, inclusive entre os formadores de professores de matemática".

Tendo em vista essas asserções acerca das concepções de ensino e aprendizagem que influenciaram e, em muitos casos ainda influenciam a formação do professor, podemos questionar como os órgãos educacionais têm pensado os aspectos concernentes à formação do professor.

A nova Lei de Diretrizes e Bases da Educação Nacional - LDB - que estabelece as diretrizes e bases da educação nacional foi aprovada no dia 20/12/1996 e assinala um momento de transição para a educação brasileira. O documento apresenta 9 "blocos" de discussão, denominados de Título I, II, e assim sucessivamente e que tratam de diferentes assuntos: 1) "Da educação"; 2) "Dos princípios e fins da educação nacional"; 3) "Do direito à educação e do dever de educar"; 4) "Da organização da educação nacional"; 5) "Dos níveis e das modalidades de educação e ensino"; 6) "Dos profissionais da educação"; 7) "Dos recursos financeiros"; 8) "Das disposições gerais"; e 9) "Das disposições transitórias" (LDB, 1996).

Alguns desses "blocos" contêm informações e dados relevantes aos nossos propósitos. Nesse sentido, no que se refere aos profissionais da educação, a LDB expõe que a finalidade da formação para esses profissionais é "atender aos objetivos dos diferentes níveis e modalidades de ensino e às características de cada fase do desenvolvimento do educando" (LDB, 1996, p. 22). 
Ainda de acordo com a Lei, para o cumprimento dessa finalidade, a formação dos profissionais da educação terá dois fundamentos: 1) a associação entre teorias e práticas, inclusive mediante a capacitação em serviço; e 2) aproveitamento da formação e experiências anteriores em instituições de ensino e outras atividades.

Nessa mesma perspectiva, isto é, abordando aspectos da formação dos professores, mas de modo particular, a formação inicial, Pires (2002) destaca três princípios:

I. A concepção de competência é nuclear na orientação de um curso de formação inicial de professores; II. Coerência entre a formação oferecida e a prática esperada do futuro professor; III. A pesquisa é elemento essencial na formação profissional do professor (p. 45).

Em acréscimo ao exposto por Pires (2002), a Proposta de Diretrizes para a Formação Inicial de Professores da Educação Básica, em nível superior, indica que "os conteúdos curriculares não têm sustentação em si mesmos, mas constituem meios para que os alunos da Educação Básica possam desenvolver capacidades e constituir competências" (BRASIL, 2000, p. 38).

Nesse sentido, Burak (2003, p. 27) efetua a seguinte afirmação:

[...] as discussões dos cursos de Licenciatura no âmbito curricular devem apresentar uma mudança no enfoque até então apresentado. Enquanto as discussões tinham como enfoque a visão disciplinar, a nova proposta para a Licenciatura em Matemática e outras áreas apresenta como foco as competências a serem construídas durante a formação do futuro professor para a Educação Básica.

Essas competências, de acordo com Brasil (2000, p. 65), "tratam sempre de alguma forma de atuação, só existem 'em situação' e, portanto, não podem ser aprendidas pela comunicação de ideias". Em outras palavras, “[...] não basta a um profissional ter conhecimento sobre seu trabalho, é fundamental que saiba fazê-lo".

No intuito de contribuir para que o professor sinta-se preparado para a sua atuação em sala de aula, Burak (2003) relata que a formação inicial de professores deve estimular e favorecer a inserção do futuro profissional na escola em situações com as quais irá conviver e precisa intervir de forma adequada e produtiva.

No que se refere aos investimentos no âmbito da formação do professor, o PNE - Plano Nacional de Educação - aprovado no ano de 2010, 
considera importante "ampliar programa de iniciação à docência a estudantes matriculados em cursos de licenciatura, a fim de aprimorar a formação de profissionais para atuar no magistério da educação básica" (p. 46).

Além disso, o plano indica como objetivos

15.6) promover a reforma curricular dos cursos de licenciatura $\mathrm{e}$ estimular a renovação pedagógica, de forma a assegurar o foco no aprendizado do/a aluno/a, dividindo a carga horária em formação geral, formação na área do saber e didática específica e incorporando as modernas tecnologias de informação e comunicação; 15.7) garantir, por meio das funções de avaliação, regulação e supervisão da educação superior, a plena implementação das respectivas diretrizes curriculares (p. 47).

Tendo em vista, as propostas dos documentos oficiais e os argumentos de alguns autores, apresentados no texto, se faz necessário repensar a formação de professores, de tal modo que se busque colocar em prática o que está sendo proposto. Uma vez que pesquisas que focam aspectos da formação do professor têm mostrado fragilidades nesse contexto. Isto é, revela-se que existem propostas para uma formação de qualidade, mas há um caminho a ser percorrido até que elas sejam incorporadas nos programas de formação inicial e continuada.

Nesse sentido, Burak (2003) apresenta as manifestações de alguns professores acerca das divergências entre a formação que tiveram e a sua prática docente. Dentre as falas dos professores, destacamos que eles sentemse despreparados para fazer frente às demandas efetuadas pelas diretrizes; há um distanciamento da realidade em que o professor foi formado e a realidade encontrada no contexto da sala de aula; não existe, ou é muito pequena, a contextualização na maioria das disciplinas. Isto é, "há uma completa desarticulação entre a teoria e prática durante a sua formação" (p. 23).

Em outra pesquisa, os professores apontam

[...] lacunas, falhas e carências em suas formações acadêmicas, $o$ que os leva à procura de cursos de formação continuada ou outros momentos de formação contínua que possam possibilitar, assim, uma imersão na prática da sala de aula numa abordagem distinta da tradicional, o que não foi possível em sua formação "inicial" na graduação (GARNICA, 2005, p. 5).

Ainda nesse contexto, Pimenta (1996, p. 73) afirma que "[...] os cursos de formação, ao desenvolverem um currículo formal com conteúdos e 
atividades de estágios distanciados da realidade das escolas [...] pouco têm contribuído para gestar uma nova identidade profissional docente". Talvez visualizando esse contexto dos cursos de formação, citados aqui pela autora, a proposta das Diretrizes Curriculares para as Licenciaturas destaca que

[...] a perspectiva de formação profissional apresentada nesse documento inverte a lógica que tradicionalmente presidiu a organização curricular: em lugar de partir de uma listagem de disciplinas obrigatórias e respectivas cargas horárias, o paradigma exige tomar como referência inicial o conjunto de competências que se quer que o professor constitua no curso (BRASIL, 2001, p. 51).

Além disso, essa mesma proposta traz a necessidade de que os cursos de formação proporcionem aos futuros professores situações em que eles possam, ao mesmo tempo, colocar em prática e mobilizar conhecimentos de diferentes naturezas e experiências.

A partir do exposto, revela-se que muitas são as propostas direcionadas à formação do professor. Propostas que visam uma formação voltada aos aspectos mais amplos e não apenas aos conteúdos disciplinares. Isso se deve, dentre outros aspectos, ao fato de que o trabalho do professor não se restringe somente a cumprir determinados tópicos de conteúdos ou finalizar um livro didático. A profissão "ser professor" envolve características mais abrangentes.

Nesse sentido, isto é, sabendo o quanto são amplas as questões relacionadas à formação do professor, concordamos com Tardif (2012, p. 241) quando relata que é estranho que "a formação de professores tenha sido e ainda seja bastante dominada por conteúdos e lógicas disciplinares e não profissionais". Isso pode indicar a ausência de formação ou a repetição de posturas pedagógicas e metodológicas que os próprios formadores de professores foram submetidos, num paradigma disciplinar.

Ressaltamos que, com esse argumento, não estamos atribuindo a responsabilidade da formação do professor exclusivamente aos professores que atuam nas licenciaturas. Mas sim, que esses professores também precisam buscar alternativas que possibilitem uma formação inicial significativa, da mesma maneira que é exigido dos professores da Educação Básica um processo de ensino e aprendizagem que proporcione aos seus alunos muito mais do que a memorização de fórmulas e de procedimentos para a resolução de um exercício. Nesse contexto desejável, a adoção da Modelagem Matemática e a compreensão do seu alcance pedagógico permitem alcançar algumas destas exigências. E isso, requer, por exemplo, amplo conhecimento 
de Modelagem na Educação Matemática, por parte dos professores atuantes na licenciatura, uma vez que ela transcende a lógica da disciplina, por ser essencialmente, interdisciplinar.

Desse modo, tendo em vista a presença ainda constante de uma formação pautada em aspectos mais pontuais, na sequência, buscamos explicitar algumas reflexões acerca da formação inicial de professores e a Modelagem Matemática na Educação Básica, com o objetivo de construir um olhar diferenciado sobre a formação e sobre essa tendência metodológica que é amplamente divulgada, mas que ainda é distante do contexto da sala de aula.

\section{Formação de professores e a Modelagem Matemática}

Segundo D’Ambrósio. B(1993) há a necessidade de que os professores de Matemática compreendam a disciplina em termos investigativos. Isto é,

[...] uma disciplina em que o avanço se dá como consequência do processo de investigação e resolução de problemas. Além disso é importante que o professor entenda que a Matemática estudada deve, de alguma forma, ser útil aos alunos, ajudando-os a compreender, explicar ou organizar sua realidade (p. 35).

Essa afirmação da autora incide direta ou indiretamente na questão da formação do professor, uma vez que é nela que, supostamente, os professores deveriam ter contato com aspectos mais abrangentes da sua atuação profissional, dentre eles, aqueles que se voltam à sua disciplina de atuação.

Além disso, a partir dessa afirmação, podemos fazer apologia à utilização da Modelagem Matemática no contexto da sala de aula, tendo em vista que essa tendência metodológica pressupõe um processo de ensino e aprendizagem voltado à solução efetiva de problemas reais e que estão relacionados aos interesses dos próprios alunos.

Justificando a utilização da Modelagem Matemática em sala de aula estamos, também, defendendo uma formação de professores voltada a essa tendência, pois concordamos com o fato de que "[...] ninguém promove o desenvolvimento daquilo que não desenvolveu em si mesmo, ou torna-se difícil promover a aprendizagem de conteúdos que não domina, ou a autonomia que não teve a oportunidade de construir" (BRASIL, 2000, p. 68).

Ressaltamos, também que essa defesa vai ao encontro de alguns dos objetivos do Plano Nacional de Educação, que indicam, de um modo geral, uma renovação pedagógica nos cursos de licenciatura e a implementação das respectivas diretrizes curriculares. Dizemos que vai ao encontro, uma 
vez que a Modelagem Matemática propõe um processo de ensino e aprendizagem diferente daquele conhecido como tradicional e está presente, por exemplo, nas diretrizes curriculares do estado do Paraná.

Além desse argumento, para Costa (2002), citada por Meyer, Caldeira e Malheiros (2011), a formação de professores,

tendo como pressupostos básicos os fundamentos epistemológicos que sustentam uma pedagogia que tem como um dos focos a Modelagem Matemática, vai se dar na tentativa de superar a neutralidade e apontar para novas linguagens, como, por exemplo, as noções de sujeito, identidade, razão e evolução / progresso, desarmando, assim, os princípios, eminentemente cientificistas e acadêmicos (p. 61).

Nesse contexto, "formar professores de Matemática na perspectiva da Modelagem passa pelo questionamento (e, quem sabe, pela negação) do direito de universalizar o particular, de igualar as diferenças e da pretensão de abarcar a totalidade" (MEYER; CALDEIRA; MALHEIROS, 2011, p. 62).

Mais do que passar pelo questionamento, a Modelagem Matemática na formação do professor, segundo Dias e Almeida (2004, p. 7), visa alcançar, de certa forma, "autonomia em relação ao conhecimento profissional", pois quando essa tendência metodológica é utilizada em sala de aula, independentemente do nível de ensino, ela pode favorecer o desenvolvimento, a apropriação e o domínio de processos complexos de pensamento.

Dito de outro modo exige do professor mais do que os conhecimentos da sua disciplina de atuação. Requer um cuidado e uma valorização das ideias e conjecturas dos alunos, um olhar para os diferentes assuntos interdisciplinares que podem surgir em uma atividade de Modelagem, bem como os diferentes conteúdos matemáticos que podem ser solicitados nessa atividade, distanciando-se assim da concepção tradicional de que os conteúdos abordados devam seguir uma ordem pré-estabelecida e tida como linear.

Assim, levando em consideração que a formação do professor em Modelagem exige uma postura diferenciada, revela-se a necessidade em se assumir tanto a formação de professores como a Modelagem Matemática em aspectos mais abrangentes. Significa, segundo Meyer, Caldeira e Malheiros (2011, p. 63) "em desmontar uma estrutura em que o importante é somente a transmissão de conhecimentos sistematizados ao longo do processo de educação". 
Explicitados alguns dos argumentos que aproximam a formação do professor em Modelagem daquilo que é sugerido pelos documentos oficiais relacionados à formação do professor, apresentamos na sequência pesquisas que têm sido desenvolvidas nessa temática. Essas tendem a contribuir para que a Modelagem chegue aos cursos de graduação e também às atividades desenvolvidas no contexto da formação continuada.

Acreditamos que essa apresentação se faça necessária, por ser a formação do professor em Modelagem um assunto cuja abordagem em pesquisas se deu recentemente. Ainda, por entendermos que muitas vezes o primeiro ou o único contato com a Modelagem se dê por meio dessas pesquisas, pois, de um lado, muitos dos professores que já atuam na Educação Básica não tiveram a Modelagem Matemática em seus cursos de formação inicial e, de outro, pelo fato de essa tendência possuir ainda uma pequena inserção em atividades de formação continuada.

As pesquisas, em nível de mestrado e doutorado, desenvolvidas nessa temática e mapeadas por nós em outra oportunidade no Banco de Teses da Capes, são recentes, sendo que a primeira delas foi realizada no ano de $2001^{3}$.

O levantamento dessas pesquisas coloca em destaque que a preocupação em estudar a formação do professor em Modelagem Matemática se deu em um momento posterior à ênfase na formação do professor de matemática em aspectos gerais. Essa afirmação vai ao encontro do exposto por Bicudo (2003), quando enfatiza que o olhar para a formação de professores se inicia a partir da década de 1980 .

Os trabalhos mapeados, cujo foco estava centrado na formação do professor em Modelagem, apresentavam como sujeitos professores ou futuros professores participantes de cursos de formação inicial ou atividades de formação continuada que foram ofertados na modalidade presencial ou na modalidade de educação a distância $(\mathrm{EaD})$. Como objetivos, as pesquisas apresentavam, de um modo geral: 1) a investigação das impressões, das experiências, das tensões e das concepções de professores e futuros professores envolvidos com Modelagem Matemática; 2) a análise da apropriação ou não da Modelagem no processo de ensino e aprendizagem da Matemática por parte dos professores; e 3) o estabelecimento de um sistema de ensino e aprendizagem à distância de Modelagem Matemática para professores e futuros professores de Matemática.

\footnotetext{
3 TAMBARUSSI, Carla Melli; KLÜBER, Tiago Emanuel. Focos da pesquisa stricto sensu em Modelagem Matemática na Educação Matemática brasileira: considerações e reflexões. Educação Matemática Pesquisa. São Paulo, v. 16, n. 1, p. 209-225, 2014.
} 
Esse mapeamento efetuado por nós, também ressalta a ênfase em inserir a Modelagem Matemática no contexto da sala de aula, tendo em vista o potencial atribuído a essa tendência no que se refere à diversidade metodológica. Contudo, essa inserção apresenta uma preocupação diferenciada. Há nessas pesquisas indícios de que sem um investimento na formação do professor, a inserção da Modelagem Matemática na sala de aula não se diferencie da prática enraizada nas escolas, na qual os alunos foram acostumados a receber o conteúdo matemático como algo fragmentado e sem relação com o seu dia a dia.

\section{Uma metacompreensão sobre o exposto}

Escrever um ensaio sobre a formação de professores em Modelagem Matemática é, desde o próprio objeto, um desafio. Como o próprio texto revelou é uma seara de múltiplos argumentos e intencionalidades distintas. No entanto, isso não é motivo para não nos posicionarmos. Assim, de toda a discussão efetuada, podemos apontar alguns elementos que decorrem de uma metasíntese sobre o exposto.

A Modelagem Matemática por suas características investigativas, interdisciplinares e temáticas torna-se relevante no contexto das atuais diretrizes para a formação de professores da Educação Básica brasileira. Sabemos que esse argumento não é novidade, mas dele emergem outros em tom de indagação.

Se a Modelagem Matemática é relevante quais são os empecilhos para que ela não esteja plenamente contemplada, por exemplo, nas licenciaturas? Poderíamos destacar vários, mas o principal deles é aquele que diz respeito às concepções de currículo, educação e sobre a profissão docente. Estes, por vezes, são marcados por imediatismos e por visões fragmentadas da produção de conhecimentos práticos e teóricos e que acabam por influenciar diretamente o processo de ensino e aprendizagem.

Em termos de legislações apresentadas neste ensaio, revelou-se ao menos dois aspectos que incidem diretamente no nosso objeto de estudo, quais sejam: 1) uma ampla abertura ao acolhimento da Modelagem Matemática; e 2) propostas de uma formação de professores voltadas às características mais abrangentes.

Entretanto, como descrevemos por meio de outras pesquisas, os cursos de formação estão permeados de concepções pontuais de ensino e aprendizagem e que abarcam, de um modo geral, uma perspectiva tradicionalista. Nesse sentido, é portanto de se esperar que esses cursos tenham dificuldades 
em assumir tendências metodológicas que rompam com aquilo que já está instalado e tido por corriqueiro nos cursos de formação de professores de Matemática.

Diante das recentes pesquisas sobre formação de professores em todas as áreas, como também apresentamos, há um confronto de forças entre a cultura de formação de professores que é disseminada e o ideal que se pretende. Esse confronto revela, por vezes, lacunas, por exemplo, nas próprias práticas de Modelagem. Em outras palavras, podemos afirmar que mesmo as pesquisas desenvolvidas no enfoque da formação do professor da Educação Básica apresentam, em muitos casos, modelos de processos formativos antiquados ou, ainda mais, inapropriados às características investigativas, interdisciplinares e temáticas da Modelagem.

Por essas razões, a formação de professores em Modelagem Matemática precisa não apenas vencer os métodos tradicionais de ensino de Matemática, mas os métodos tradicionais das concepções amplamente conhecidas de formação de professores. Somente com esse enfrentamento tornar-se-á possível a sua plena inserção e, segundo Klüber (2012), deixar de ser alternativa para se tornar uma das principais diretrizes quando se pensam os processos de ensino e aprendizagem da Matemática.

\section{Referências}

BARBOSA, J. C. Modelagem na Educação Matemática: Contribuições para o detabe teórico. In: Reunião Anual da ANPED, 24, 2001. Caxambu. Anais... Caxambu: AMPED, 2001.

. Modelagem matemática: O que é? Por que? Como? Veritati. n. 4, 2004. p. 73-80.

BICUDO, M. A. V. (Org.). Formação de Professores? Da incerteza à compreensão. Bauru: EDUSC, 2003.

BURAK, D. Modelagem matemática: uma alternativa para o ensino de matemática na $5^{\mathrm{a}}$ série. Rio Claro, 1987. Dissertação (Mestrado em Educação Matemática) - Programa de Pós-Graduação em Educação Matemática. Universidade Estadual Paulista Júlio de Mesquita Filho, 1987.

. Modelagem matemática: ações e interações no processo de ensino aprendizagem. Campinas, 1992. Tese (Doutorado em Educação) - Programa de Pós-Graduação em Educação. Universidade Estadual de Campinas, 1992. 
. O papel da Universidade e o comprometimento profissional na formação de professores para a educação básica. Perspectiva, Erechim, v. 27, n. 98, p.17-31, jun. 2003.

. A Modelagem matemática e a Sala de Aula. In: Encontro Paranaense de Modelagem na Educação Matemática, 1, 2004. Anais... Londrina: UEL. p. 1-10. 2004.

; ARAGÃO, R. M. R. de. A modelagem matemática e relações com a aprendizagem significativa. Curitiba: CRV, 2012.

BRASIL. Lei de Diretrizes e Bases da Educação Nacional. Lei número 9394, 20 de dezembro de 1996.

BRASIL. Ministério da Educação. Secretaria de Educação Média e Tecnológica. Parâmetros Curriculares Nacionais: ensino médio. Brasília: MEC/SEMTEC, 1999.

BRASIL. Ministério da Educação. Proposta de diretrizes para a formação inicial de professores da educação básica, em nível superior. Brasília, 2000.

BRASIL. Ministério da Educação. Diretrizes Curriculares Nacionais para a Formação de Professores da Educação Básica, em nível superior, curso de licenciatura, de graduação plena. Brasília, 2001. Disponível em: http:// portal.mec.gov.br/cne/arquivos/pdf/009.pdf. Acesso: 17/08/2014.

DIRETRIZES Curriculares Nacionais para a Formação de Professores da Educação Básica, em nível superior, curso de licenciatura, de graduação plena CONFERÊNCIA NACIONAL DE EDUCAÇÃO (CONAE), 2010, Brasília, DF. Construindo o Sistema Nacional Articulado de Educação: o Plano Nacional de Educação, diretrizes e estratégias, Brasília, DF: MEC, 2010.

D’AMBRÓSIO, B. Formação de professores de Matemática para o século XXI: o grande desafio. Pro-posição, Campinas, 4, p. 35-42, 1993.

D’AMBROSIO, U. A Matemática nas escolas. Educação Matemática em Revista, A 9, n. 11, p. 29-33, 2002.

DIAS, M. R.; ALMEIDA, L. M. W. de. Formação de professores e modelagem matemática. In: Encontro Nacional de Educação, 8. 2004, Recife. Anais... Recife: SBEM, 2004. 
FIORENTINI, D. Alguns modos de ver e conceber o ensino de Matemática no Brasil. Revista Zetetiké, ano 3 n 4. UNICAMP - Campinas, 1995.

GARNICA, A. V. M.; MODESTO, M.A. Ouvindo Professores de Matemática: um estudo sobre formação (continuada). Guairaca, Guarapuava, Paraná, v. 19 , p. 31-55, 2005.

KLÜBER, T. E. (Des) Encontros entre a modelagem matemática na Educação Matemática e a Formação de Professores de Matemática. Alexandria, v. 5, n. 1, p. 63-84, maio 2012.

MEYER, J. F. da C. de A.; CALDEIRA, A. D.; MALHEIROS, A. P. dos S. Modelagem em Educação Matemática. Belo Horizonte: Autêntica, 2011.

PARANÁ, Secretaria de Estado da Educação. Diretrizes curriculares da educação básica: matemática. Curitiba: SEED, 2008.

PIMENTA, S. G. Formação de professores: saberes da docência e identidade do professor. Revista Faculdade de Educação. São Paulo, v. 22, n. 2, p. 72-89. 1996.

PIRES, C. M. C. Reflexões sobre os cursos de licenciatura em matemática. Educação Matemática em Revista. Edição especial, São Paulo, p. 44-56, 2002.

SEVERINO, A. J. Metodologia do trabalho científico. São Paulo: Cortez, 2000 .

TARDIF, M. Saberes Docentes e formação profissional. 13 ed. Petrópolis, RJ: Vozes, 2012. 